\title{
The Role of Genetic and Immune Factors for the Pathogenesis of Primary Sclerosing Cholangitis in Childhood
}

\author{
Priscila Menezes Ferri, ${ }^{1}$ Ana Cristina Simões e Silva, ${ }^{1,2,3}$ Soraya Luiza Campos Silva, \\ Diego Junior Queiroga de Aquino, ${ }^{1}$ Eleonora Druve Tavares Fagundes, ${ }^{1}$ \\ Débora Marques de Miranda, ${ }^{1,2}$ and Alexandre Rodrigues Ferreira ${ }^{1}$ \\ ${ }^{1}$ Department of Pediatrics, UFMG, 30130-100 Belo Horizonte, MG, Brazil \\ ${ }^{2}$ Instituto Nacional de Ciência e Tecnologia de Medicina Molecular, INCT-MM, CNPq-FAPEMIG, \\ Universidade Federal de Minas Gerais, 30130-100 Belo Horizonte, MG, Brazil \\ ${ }^{3}$ Laboratório Interdisciplinar de Investigação Médica, Avenida Alfredo Balena 190, 2nd Floor, Room 281, \\ 30130-100 Belo Horizonte, MG, Brazil
}

Correspondence should be addressed to Ana Cristina Simões e Silva; acssilva@hotmail.com

Received 5 May 2016; Accepted 16 October 2016

Academic Editor: Antonios Athanasiou

Copyright (C) 2016 Priscila Menezes Ferri et al. This is an open access article distributed under the Creative Commons Attribution License, which permits unrestricted use, distribution, and reproduction in any medium, provided the original work is properly cited.

\begin{abstract}
Primary sclerosing cholangitis (PSC) is a rare cholestatic liver disease characterized by chronic inflammation of the biliary tree resulting in liver fibrosis. PSC is more common in male less than 40 years of age. The diagnosis of PSC is based on clinical, laboratory, image, and histological findings. A biochemical profile of mild to severe chronic cholestasis can be observed. Endoscopic retrograde cholangiography is the golden standard method for diagnosis, but magnetic resonance cholangiography is currently also considered a first-line method of investigation. Differences in clinical and laboratory findings were observed in young patients, including higher incidence of overlap syndromes, mostly with autoimmune hepatitis, higher serum levels of aminotransferases and gamma-glutamyl transferase, and lower incidence of serious complications as cholangiocarcinoma. In spite of the detection of several HLA variants as associated factors in large multicenter cohorts of adult patients, the exact role and pathways of these susceptibility genes remain to be determined in pediatric population. In addition, the literature supports a role for an altered immune response to pathogens in the pathogenesis of PSC. This phenomenon contributes to abnormal immune system activation and perpetuation of the inflammatory process. In this article, we review the role of immune and genetic factors in the pathogenesis of PSC in pediatric patients.
\end{abstract}

\section{Introduction}

Autoimmune liver diseases are infrequent in children and adolescents, but, when diagnosed, prompt treatment has utmost importance. Among these conditions, primary sclerosing cholangitis (PSC) is a rare cholestatic liver disease characterized by chronic inflammation of the biliary tree resulting in liver fibrosis. An important factor for the occurrence of cirrhosis is the toxic effect of bile stasis $[1,2]$. In contrast with the female predominance of many autoimmune diseases, approximately $2 / 3$ of the PSC patients are males aged less than 40 years [3].

PSC has a wide-ranging clinical presentation, from asymptomatic patients to chronic liver disease $[4,5]$. As a result, the diagnosis can be a big challenge, especially in young patients. Cholestatic bile diseases are usually associated with other autoimmune conditions, including ulcerative colitis (UC) and autoimmune hepatitis, referred to as the overlap syndromes $[6,7]$. The named AIH-PSC syndrome is more frequent in children and adolescents than in adult patients; the disease evolves with typical features of PSC in cholagiography or histology, associated with laboratory and histological characteristics of AIH. In AIH-PSC, the reaction to treatment is also different, since patients have better response to immunosuppression than the isolated form of PSC [7].

The diagnosis of PSC is based on clinical, laboratory, and image findings. A biochemical profile of mild to 
severe chronic cholestasis can be observed [8]. Endoscopic retrograde cholangiography is the golden standard method to detect PSC. The exam shows multifocal areas of strictures of intra- and/or extrahepatic bile ducts, with intervening segments of normal or dilated ducts $[8,9]$. In addition, magnetic resonance cholangiography (MRC) is also considered a firstline image method for PSC diagnosis, being noninvasive and reliable $[8,10,11]$.

Multiple autoantibodies can be useful in detecting PSC, but none of them solely allows the diagnosis [12]. Serum atypical perinuclear antineutrophil cytoplasmic antibody ( $\mathrm{p}$ ANCA) is the most common autoantibody detected in PSC, but with a weak association [13-15]. The second commonest autoantibodies are anti-Saccharomyces cerevisiae antibodies (ASCA), which also exhibit high frequency even in the absence of advanced disease or inflammatory bowel disease (IBD) [16]. Recently, Jendrek et al. [17] also found an association between antibodies against glycoprotein 2 (antiGP2) and large bile duct diseases with considerable rates. In PSC, anti-GP2 IgA was consistently identified in patients with poor survival during follow-up, being associated with cholangiocarcinoma [17]. Other autoantibodies including antinuclear antibody (ANA) and liver kidney microsomal type 1 antibody (anti-LKM1) can be positive in PSC patients, but with low specificity for the diagnosis of the disease [18].

PSC has no effective medical treatment and, in many cases, the disease will lead to cirrhosis and end-stage liver disease with need of liver transplantation $[1,5,19,20]$. Ursodeoxycholic acid (UDCA) has been administered as a palliative measure, without interfering with clinical outcome $[21,22]$. Since clinical tools have been insufficient to characterize and to predict the outcome, the aim of this review is to summarize evidence from literature about the potential role of immune and genetic factors in the pathogenesis of PSC in pediatric patients.

\section{Genetic Factors}

The pathogenesis of PSC is still not fully understood, but a complex interaction between genetic, immunological, and environmental factors with breakdown of self-tolerance has been reported $[14,23]$. Studies have shown a strong genetic predisposition in PSC, with first-degree relatives exhibiting 9to 39-fold increased risk to develop the disease [24]. Genome studies showed that this genetic tendency is mainly associated with human leukocyte antigen (HLA) complex II (MHC II) chromosome 6p21 [25-29]. Some haplotypes are considered as main susceptibility factors. HLA-B and HLA-DRB1 alleles are the most important ones. Among them, the most frequent are HLA-A1-B8-DRB1 $* 0301-D Q B 1 * 0201$, HLADRB1 $* 1301$ $\mathrm{DCB} 1 * 0603$, and HLA-DRB1*1501-DQB1*0602 [25-27, 30, 31]. As protective haplotypes, HLA-DRB1*04-DQB1*0302 and HLA-DRB1*0701-DQB1*0303 have been reported [25, $26,31]$. In spite of the detection of several HLA variants as associated factors in large multicenter cohorts of adult patients, the exact role and pathways of these susceptibility genes remain to be determined in pediatric population [2529].
Table 1 is a compilation of relevant studies that have investigated the influence of MHC II antigens in PSC. The number of children evaluated in these studies is also shown.

Other studies have proposed the existence of MHC class I region genes and non-HLA risk loci for PSC, supporting that other genetic factors take part in the pathogenesis of the disease. Wiencke et al. [43] evaluated the extended HLA class I region genes as contributing factors to modulate immune response or to confer susceptibility in PSC patients. The authors found a significant association with alleles $\mathrm{MIB} * 349$, D6S265*122, D6S464*209, and D6S2225*147, all being secondary to DR3 (HLA-DRB1*03) associations [43]. D6S265*122 was also associated with DR6 [40]. The study of Karlsen et al. [44] showed that killer immunoglobulinlike receptors (KIRs) and HLA class I ligands can be also associated with PSC.

Norris et al. [45] described an association between the $M I C A * 008$ allele and PSC. MICA*008 is one of the components of a group of polymorphic genes on chromosome 6. $M I C A * 008$ is a stress and heat shock inducible molecule that activates inflammatory response as a ligand for $\gamma \delta$ T cells, natural killer $(\mathrm{NK})\left(\mathrm{CD}^{2} 6^{+}\right)$cells, and cells expressing the NKG2D receptor [42].

Non-HLA findings include modifications in genes related to autoimmunity (IL2/IL2RA), bile acid toxicity (GPBAR1), and mechanisms related to concomitant IBD (IL2/IL21, ILR2A, CARD9, MST1, Fut2, and SIK2) [27, 46]. Karlsen et al. [25] also investigated genome-wide association in PSC. These authors detected a susceptibility variant of importance for inflammatory conditions at chromosome 13q31, with GPC5/GPC6 as a candidate to this association [25]. Despite its involvement in inflammatory pathways, the precise function of GPC6 in the liver and bile ducts remains unknown and more studies are needed to clarify the role of this molecule.

As shown, most of these studies evaluated only adults, creating a gap in relation to the findings of pediatric patients. Indeed, PSC in children seems to be different from the disease in adults $[44,45]$. In this regard, differences in clinical and laboratory findings observed in young patients include higher incidence of overlap syndrome, higher serum levels of aminotransferases and gamma-glutamyl transferase, and lower incidence of serious complications as cholangiocarcinoma [44]. Thus, the results obtained for adult patients may not be always valid for children. Further studies are obviously needed to evaluate the role of immune and genetic factors in pediatric age group. Studies should analyze pediatric patients as a subgroup by separating patients who had disease onset during childhood. This strategy of analysis probably enables more reliable evaluation of the role of immune and genetic factors in pediatric PSC.

\section{Immune Factors}

The literature supports a role for an altered immune response to pathogens in the pathogenesis of PSC [14, 47]. This phenomenon contributes to abnormal immune system activation and perpetuation of an inflammatory process [14, 47]. 
TABLE 1: Publications on major histocompatibility class II human leukocyte antigens and their association with primary sclerosing cholangitis patients.

\begin{tabular}{|c|c|c|c|}
\hline Reference & $\begin{array}{l}\text { Total number of } \\
\text { patients/controls } \\
\text { (number of } \\
\text { children and } \\
\text { adolescents) }\end{array}$ & $\begin{array}{l}\text { What was } \\
\text { evaluated }\end{array}$ & Conclusions \\
\hline
\end{tabular}

$\begin{array}{lc}\text { Farrant et al. [32], } & \text { HLADRB, DQA, } \\ 1992 & \text { and DQB }\end{array}$

Farrant et al. [32],

$71 / 68(0)$

Amar et al. [33],

$1992 \quad$ 15/no control (0)

HLADRB3

Olerup et al. [34], 1995

75/250 (not cited) HLADR and DQ

HLADRB $3 * 0101$ was the most associated allele, with reduced survival of patients with it. DRB $5 * 0101$ was another susceptibility allele and $\mathrm{DRB} 4 * 0101$ demonstrated a likely protective function.

No apparent association of the alleles of the DRB3 locus in the Israeli population.

Association with DRB1*1301, DQAI $* 0103$, and DQBI $* 0603$ haplotype was confirmed, whereas DRB1 $* 04$ was only slightly underrepresented.

No difference was observed in age, presentation, liver function, histological stage, or survival between patients with different positive alleles.

\begin{tabular}{lcc}
$\begin{array}{l}\text { Leidenius et al. } \\
\text { [35], } 1995\end{array}$ & $\begin{array}{c}\text { HLA-A, B, C and } \\
\text { DR }\end{array}$ \\
\hline $\begin{array}{l}\text { Wilschanski et al. } \\
{[36], 1995}\end{array}$ & $\begin{array}{c}\text { 27/no control (all } \\
\text { children) }\end{array}$ & $\begin{array}{c}\text { HLA-B and } \\
\text { HLADR }\end{array}$
\end{tabular}

Spurkland et al. [30], 1999 256/764 (not cited)

HLADR and DQ

Boberg et al. [37], 265/no control 2001

(yes, but the number was not cited)
HLA-B8 and DR3 (DRB1*03) were associated with primary sclerosing cholangitis.

An increased incidence of HLA B8 and DR2 (DRB1 $* 15)$ but not DRw52a (DRB3*0101) was found.

Increased frequencies of $\mathrm{DRB} 1 * 03-\mathrm{DQA} 1 * 0501-\mathrm{DQB} 1 * 02$, $\mathrm{DRB} 1 * 13-\mathrm{DQA} 1 * 0103-\mathrm{DQB} 1 * 0603$, and $\mathrm{DRB} 1 * 15-\mathrm{DQA} 1 * 0102-\mathrm{DQB} 1 * 0602$ haplotypes were observed. PSC was negatively associated with DRB1 $* 04-\mathrm{DQB} 1 * 0302$ haplotype.

$\mathrm{DRB} 1 * 03-\mathrm{DQA} 1 * 0501-\mathrm{DQB} 1 * 02$ (i.e., DR3, DQ2) heterozygous genotype was associated with an increased risk of death or liver transplantation. Presence of a DQ6 encoding haplotype (DQB1*0603 or DQB1*0602) in DR3, DQ2 negative individuals was associated with a reduced risk of death or liver transplantation.

Associations with the DRB3*0101DRB1 $* 0301-\mathrm{DQA1} * 0501-\mathrm{DQB} 1 * 0201$ and DRB1 $* 1301-\mathrm{DQA} 1 * 0103-\mathrm{DQB} 1 * 0603$ haplotypes were confirmed. Protective influence of the DRB1 $* 04-\mathrm{DQB} 1 * 0302$ haplotype was reaffirmed.

A previously unreported protective haplotype was found: DRB1*0701-DQB1*0303. 
TABLE 1: Continued.

\begin{tabular}{|c|c|c|c|}
\hline Reference & $\begin{array}{l}\text { Total number of } \\
\text { patients/controls } \\
\text { (number of } \\
\text { children and } \\
\text { adolescents) }\end{array}$ & $\begin{array}{l}\text { What was } \\
\text { evaluated }\end{array}$ & Conclusions \\
\hline $\begin{array}{l}\text { Bittencourt et al. } \\
{[38], 2002}\end{array}$ & $63 / 83(27)$ & $\begin{array}{l}\text { HLA-B, DRB1, } \\
\text { DQB1 }\end{array}$ & $\begin{array}{l}\text { No increase in the frequency of } \\
\text { HLA-B, DRB3, DRB } 4 \text {, or DRB } 5 \text { alleles } \\
\text { was observed. } \\
\text { The frequency of HLA-DRB } * 1301 \text { and } \\
\text { HLA-DQB } * 06 \text { was significantly } \\
\text { increased in PSC patients. }\end{array}$ \\
\hline $\begin{array}{l}\text { Neri et al. [39], } \\
2003\end{array}$ & $64 / 183(0)$ & $\begin{array}{c}\text { HLA-DRB1, } \\
\text { HLA-DQB1, and } \\
\text { HLA-B }\end{array}$ & $\begin{array}{l}\text { Frequencies of } \\
\text { DRB } 1 * 01-\mathrm{DQA} 1 * 0101-\mathrm{DQB} 1 * 0102 \text {, } \\
\mathrm{DRB} 1 * 16-\mathrm{DQA} 1 * 0102-\mathrm{DQB} 1 * 0502 \text {, } \\
\text { and DRB } 1 * 04-\mathrm{DQA} 1 * 03-\mathrm{DQB} 1 * 0301 \\
\text { haplotypes were more elevated in PSC } \\
\text { patients. } \\
\text { DRB } 1 * 07-\mathrm{DQA} 1 * 0201-\mathrm{DQB} 1 * 02 \\
\text { haplotype frequency was significantly } \\
\text { decreased in patients. }\end{array}$ \\
\hline $\begin{array}{l}\text { Karlsen et al. [25], } \\
2010\end{array}$ & $\begin{array}{c}285 / 298 \text { (yes, but } \\
\text { the number was } \\
\text { not cited) }\end{array}$ & HLADR and DQ & $\begin{array}{l}\text { The strongest association was detected } \\
\text { for HLA-B } * 08 \text { and associations with } \\
\text { the DRB } 1 \text { alleles -DRB } 1 * 03 \text {, } \\
\text {-DRB } * 04,-\mathrm{DRB} 1 * 07 \text {, and } \\
\text {-DRB } * 1301 \text { also were confirmed. }\end{array}$ \\
\hline $\begin{array}{l}\text { Hov et al. [40], } \\
2010\end{array}$ & 78/79 (not cited) & HLADRB1, HLA-C & $\begin{array}{l}\text { Positive association of PSC with } \\
\text { HLADRB } 1 * 15 \text {, } \\
\text {-DRB } 1 * 03,-\mathrm{DRB} 1 * 04 \text {, and } \\
\text {-DRB } 1 * 1301 \text { was confirmed. } \\
\text { A protective association with } \\
\text { HLADRB } 1 * 0701 \text { was found. }\end{array}$ \\
\hline $\begin{array}{l}\text { Wang et al. [41], } \\
2014\end{array}$ & 31/42 (all children) & $\begin{array}{c}\text { HLADR } \\
\text { haplotypes }\end{array}$ & $\begin{array}{l}\text { Frequencies of homozygous HLA } \\
\text { DRB } * 0301(\mathrm{DR} 3) \text { genes and } \\
\text { haplotype A1-B8-DR3 were higher in } \\
\text { patients. } \\
\text { Frequencies of disease-protective } \\
\text { genes DR } 4 \text { and/or DR15 were lower in } \\
\text { the patients. }\end{array}$ \\
\hline $\begin{array}{l}\text { Næss et al. [42], } \\
2014\end{array}$ & $\begin{array}{c}365 / 368 \text { (yes, but } \\
\text { the number was } \\
\text { not cited) }\end{array}$ & & $\begin{array}{l}\text { HLADRB } 1 * 1301-D Q B 1 * 0603 \text { and } \\
\text { DRB } 1 * 1501 \text { haplotypes conferred risk } \\
\text { for PSC. } \\
\text { HLADRB } 1 * 04-D Q B 1 * 03 \text {, } \\
\text { DRB } 1 * 0701-D Q * 0303 \text {, and DR } 13: X X \\
\text { (all non- } 13: 01 \text { alleles)-DQB } * 06 \\
\text { demonstrated a protective effect. }\end{array}$ \\
\hline
\end{tabular}

HLA: human leukocyte antigen; MHC: major histocompatibility complex; PSC: primary sclerosing cholangitis.

Cholangiocytes, after antigenic stimulus, release proinflammatory mediators that stimulate immune cells. The interaction between toll-like receptors (TLRs) and patternassociated molecular patterns (PAMPs) promotes a persistent inflammatory environment for cholangiocytes [48, 49]. TLR activation can increase the expression of interleukin-6 (IL6) and of cluster for differentiation 44 (CD44) that acts as an adhesion molecule for lymphocytes [48]. Along with this process, tumor necrosis factor (TNF), IL-6, and IL-8, released by cholangiocytes and immune cells, trigger the recruitment and activation of T lymphocytes, macrophages, neutrophils,
NK, and mesenchymal cells [14, 50-53]. In addition, senescence has been recently shown to be an important pathologic process in diverse conditions, since senescence cells can be associated with proinflammatory cytokine and chemokine hypersecretion, referred to as a senescence associated secretory phenotype (SASP) [54]. In this regard, Tabibian et al. [55] showed that PSC cholangiocytes present higher expression of SASP components, including IL-6, IL-8, CCL2, and PAI1. These cells also had increased expression of N-Ras, a wellknown inducer of senescence. These findings support the role of senescence in PSC. 
An increased number of activated lymphocytes and of NK cells in peripheral blood of PSC patients were also detected $[53,56]$. However, Bo et al. [57] showed that T lymphocytes function is impaired in PSC patients when compared with health controls. In regard to NK cells, it was reported that these cells are activated by lipid antigens exposed by the MHC class I-like molecule, CD1d [58]. When activated, NK cells can play either a protective or detrimental role in autoimmune diseases [58]. In a recent study, Schrumpf et al. [59] reported that human cholangiocytes can express CD1d and that CD1d is downregulated in biliary epithelium of patients with PSC. These authors also showed that cholangiocytes unmask lipid antigens to NL cells, suggesting that this mechanism could play a role in the autoreactivity of NK cells in PSC [59].

There are some hypotheses about how cytokines and adhesion molecules may contribute to PSC pathogenesis. In this context, lymphocytes express specific receptors, $\alpha 4 \beta 7$ and CCR9, with these cells being responsible for interferon- $\gamma$ (IFN- $\gamma$ ) production, which, in turn, enhances inflammatory stimuli $[60,61]$. Additionally, due to the release of cytokines as CCL28, CXCL12, and CXCL16 and the presence of activated lymphocytes, naive $\mathrm{T}$ cells can be primed to $\mathrm{T}$ helper 1cells $[62,63]$. In line with these findings, Martins et al. [64] showed that $\gamma \delta^{+}$cells expressing CD45RO and IL-2 contribute to an activated memory mechanism that maintains the inflammatory process. Sebode et al. [65] had also described a reduction of regulatory immune cells, including $\mathrm{FOXP}^{+}$ cells and $\mathrm{T}$ reg cells, in PSC patients. Indeed, an increased production of inflammatory cytokines including IL-17, IL-21, and TNF and of IL-17A-expressing lymphocytes can be found around bile ducts [66]. In this regard, Liu et al. [29] showed novel loci related to cytokines and chemokines in patients with PSC. The authors detected six loci in which the same gene was found by more than one technique, supporting the role of these genes in PSC [29]. At position 11q23, the most strongly associated single nucleotide polymorphism (SNP), rs7937682, is located in an intron of SIK2 gene, which encodes salt-inducible kinase 2 . This protein influences the expression of both IL-10 in macrophages and Nur77, an important transcription factor in leukocytes [29]. Another relevant association was found at $12 \mathrm{q} 13$, which is an intronic SNP, rs11168249, within the HDAC7 gene, that encodes histone deacetylase 7 [29]. This molecule has been implicated in the negative selection of T cells in the thymus, a key process in the development of immune tolerance. More studies are needed to elucidate the clinical value of these genetic findings and whether these genes can also be related to pediatric PSC.

The CCR5 (chemokine receptor 5) is responsible for the recruitment of activated lymphocytes via portal expression of CCR5 ligands $[67,68]$. CCR5 also contributes to generation of $\mathrm{T}$ helper 1 immune response $[68,69]$. Despite controversial findings, some studies report that CCR5-Delta32 deletion is associated with significant reduction in cell surface expression of this chemokine receptor, thus compromising lymphocytes activation [67-69]. While Eri et al. [68] showed that CCR5-Delta32 allele frequency was significantly higher in PSC compared to controls, Melum et al. [69] did not find any statistically significant difference in the occurrence of this mutation in patients and controls.

Some studies showed that mucosal addressin cell adhesion molecule (MAdCAM-1) plays an important role in Tlymphocyte recruitment to liver tissue derived from the gut by the connection with $\beta 2$-integrin ligand $[61,67,70]$. This mechanism explains the hepatic recruitment of mucosal lymphocytes in inflammatory liver diseases. For patients with IBD and associated PSC, this pathway has been considered as a potential therapeutic target [71]. There are studies evaluating antiadhesion molecule therapies, but yet without convincing results [71].

Liaskou et al. [72] showed that when compared with CD28 ${ }^{+} \mathrm{T}$ cells, activated CD28 ${ }^{-} \mathrm{T}$ cells produce high levels of IFN $\gamma$ and TNF, leading to upregulation of intercellular cell adhesion molecule-1, HLA-DR, and CD40, which are important ligands for immune activated $\mathrm{T}$ cells. The authors also described significantly greater proportion of $\mathrm{CD} 4^{+} \mathrm{CD} 28^{-}$ and $\mathrm{CD} 8^{+} \mathrm{CD} 28^{-}$cells that infiltrate in liver tissue of patients with PSC, leading to a proinflammatory environment rich in TNF [72].

\section{Concluding Remarks}

In conclusion, HLA class I and class II are shown to be the main risk factors for PSC in the MHC, but it is time to consolidate available information and to translate research findings into applicable knowledge for clinical practice. Studies with children are infrequent, and the findings obtained in adults should not be extrapolated for this age group. Changes in immune response to pathogens, activation of T lymphocytes, and release of inflammatory and adhesion molecules also contribute to the pathogenesis of PSC. More studies are clearly needed to unveil the influence of genetic and immune factors in the pathogenesis of PSC in pediatric patients and how these markers can be used as diagnostic tools and/or therapeutic targets.

\section{Competing Interests}

There is no conflict of interests associated with any of the senior author or other coauthors.

\section{Authors' Contributions}

D. M. Miranda, E. D. Fagundes, A. R. Ferreira, and A. C. Simões e Silva designed the research; P. M. Ferri, S. L. C. Silva, and D. J. Q. Aquino performed the research; D. M. Miranda, P.M. Ferri, A. R. Ferreira, and A. C. Simoes e Silva wrote the paper; all authors reviewed the final version.

\section{Acknowledgments}

The paper is funded by CAPES, CNPq, FAPEMIG, and INCT-MM (FAPEMIG: CBB-APQ-00075-09/CNPq 573646/ 2008-2). 


\section{References}

[1] G. M. Hirschfield, T. H. Karlsen, K. D. Lindor, and D. H. Adams, "Primary sclerosing cholangitis," The Lancet, vol. 382, no. 9904, pp. 1587-1599, 2013.

[2] R. W. G. Chapman, B. A. M. Arborgh, J. M. Rhodes et al., "Primary sclerosing cholangitis: a review of its clinical features, cholangiography, and hepatic histology," Gut, vol. 21, no. 10, pp. 870-877, 1980.

[3] E. Schrumpf and K. M. Boberg, "Epidemiology of primary sclerosing cholangitis," Best Practice and Research: Clinical Gastroenterology, vol. 15, no. 4, pp. 553-562, 2001.

[4] J. E. Eaton, J. A. Talwalkar, K. N. Lazaridis, G. J. Gores, and K. D. Lindor, "Pathogenesis of primary sclerosing cholangitis and advances in diagnosis and management," Gastroenterology, vol. 145, no. 3, pp. 521-536, 2013.

[5] S. Singh and J. A. Talwalkar, "Primary sclerosing cholangitis: diagnosis, prognosis, and management," Clinical Gastroenterology and Hepatology, vol. 11, no. 8, pp. 898-907, 2013.

[6] F. Gohlke, A. W. Lohse, H. P. Dienes et al., "Evidence for an overlap syndrome of autoimmune hepatitis and primary sclerosing cholangitis," Journal of Hepatology, vol. 24, no. 6, pp. 699-705, 1996.

[7] G. V. Gregorio, B. Portmann, J. Karani et al., "Autoimmune hepatitis/sclerosing cholangitis overlap syndrome in childhood: a 16-year prospective study," Hepatology, vol. 33, no. 3, pp. 544$553,2001$.

[8] R. Chapman, J. Fevery, A. Kalloo et al., "Diagnosis and management of primary sclerosing cholangitis," Hepatology, vol. 51, no. 2, pp. 660-678, 2010.

[9] D. Gotthardt and A. Stiehl, "Endoscopic retrograde cholangiopancreatography in diagnosis and treatment of primary sclerosing cholangitis," Clinics in Liver Disease, vol. 14, no. 2, pp. 349-358, 2010.

[10] M. Dave, B. J. Elmunzer, B. A. Dwamena, and P. D. R. Higgins, "Primary sclerosing cholangitis: meta-analysis of diagnostic performance of MR cholangiopancreatography," Radiology, vol. 256, no. 2, pp. 387-396, 2010

[11] H. Ahrar, M. S. Jafarpishe, A. Hekmatnia, R. Solouki, and M. H. Emami, "Magnetic resonance cholangiography compared with endoscopic retrograde cholangiography in the diagnosis of primary sclerosing cholangitis," Journal of Research in Medical Sciences, vol. 19, no. 12, pp. 1150-1154, 2014.

[12] J. R. Hov, K. M. Boberg, and T. H. Karlsen, "Autoantibodies in primary sclerosing cholangitis," World Journal of Gastroenterology, vol. 14, no. 24, pp. 3781-3791, 2008.

[13] B. Terjung, V. Herzog, H. J. Worman et al., "Atypical antineutrophil cytoplasmic antibodies with perinuclear fluorescence in chronic inflammatory bowel diseases and hepatobiliary disorders colocalize with nuclear lamina proteins," Hepatology, vol. 28, no. 2, pp. 332-340, 1998.

[14] E. Liaskou, G. M. Hirschfield, and M. E. Gershwin, "Mechanisms of tissue injury in autoimmune liver diseases," Seminars in Immunopathology, vol. 36, no. 5, pp. 553-568, 2014.

[15] A. K. Lunder, J. R. Hov, A. Borthne et al., "Prevalence of sclerosing cholangitis detected by magnetic resonance cholangiography in patients with long-term inflammatory bowel disease," Gastroenterology, vol. 151, no. 4, pp. 660-669.e4, 2016.

[16] B. Terjung, J. Söhne, B. Lechtenberg et al., "p-ANCAs in autoimmune liver disorders recognise human $\beta$-tubulin isotype 5 and cross-react with microbial protein FtsZ," Gut, vol. 59, no. 6, pp. 808-816, 2010.
[17] S. T. Jendrek, D. Gotthardt, T. Nitzsche et al., "Anti-GP2 IgA autoantibodies are associated with poor survival and cholangiocarcinoma in primary sclerosing cholangitis," Gut, 2016.

[18] G. Maggiore, S. Riva, and M. Sciveres, "Autoimmune diseases of the liver and biliary tract and overlap syndromes in childhood," Minerva Gastroenterologica e Dietologica, vol. 55, no. 1, pp. 5370, 2009.

[19] U. Broomé, R. Olsson, L. Lööf et al., "Natural history and prognostic factors in 305 Swedish patients with primary sclerosing cholangitis," Gut, vol. 38, no. 4, pp. 610-615, 1996.

[20] T. R. Card, M. Solaymani-Dodaran, and J. West, "Incidence and mortality of primary sclerosing cholangitis in the UK: a population-based cohort study," Journal of Hepatology, vol. 48, no. 6, pp. 939-944, 2008.

[21] R. Olsson, K. M. Boberg, O. S. de Muckadell et al., "High-dose ursodeoxycholic acid in primary sclerosing cholangitis: a 5-year multicenter, randomized, controlled study," Gastroenterology, vol. 129, no. 5, pp. 1464-1472, 2005.

[22] K. D. Lindor, K. V. Kowdley, V. A. C. Luketic et al., "High-dose ursodeoxycholic acid for the treatment of primary sclerosing cholangitis," Hepatology, vol. 50, no. 3, pp. 808-814, 2009.

[23] C. L. Bowlus, "Cutting edge issues in primary sclerosing cholangitis," Clinical Reviews in Allergy and Immunology, vol. 41, no. 2, pp. 139-150, 2011.

[24] A. Bergquist, G. Lindberg, S. Saarinen, and U. Broomé, "Increased prevalence of primary sclerosing cholangitis among first-degree relatives," Journal of Hepatology, vol. 42, no. 2, pp. 252-256, 2005.

[25] T. H. Karlsen, A. Franke, E. Melum et al., "Genome-wide association analysis in primary sclerosing cholangitis," Gastroenterology, vol. 138, no. 3, pp. 1102-1111, 2010.

[26] E. Melum, A. Franke, C. Schramm et al., "Genome-wide association analysis in primary sclerosing cholangitis identifies two non-HLA susceptibility loci," Nature Genetics, vol. 43, no. 1, pp. 17-19, 2011.

[27] T. Folseraas, E. Melum, P. Rausch et al., "Extended analysis of a genome-wide association study in primary sclerosing cholangitis detects multiple novel risk loci," Journal of Hepatology, vol. 57, no. 2, pp. 366-375, 2012.

[28] B. Srivastava, G. F. Mells, H. J. Cordell et al., "Fine mapping and replication of genetic risk loci in primary sclerosing cholangitis," Scandinavian Journal of Gastroenterology, vol. 47, no. 7, pp. 820-826, 2012.

[29] J. Z. Liu, J. R. Hov, T. Folseraas et al., "Dense genotyping of immune-related disease regions identifies nine new risk loci for primary sclerosing cholangitis," Nature Genetics, vol. 45, no. 6 , pp. 670-675, 2013.

[30] A. Spurkland, S. Saarinen, K. M. Boberg et al., "HLA class II haplotypes in primary sclerosing cholangitis patients from five European populations," Tissue Antigens, vol. 53, no. 5, pp. 459469, 1999.

[31] P. T. Donaldson and S. Norris, "Evaluation of the role of MHC class II alleles, haplotypes and selected amino acid sequences in primary sclerosing cholangitis," Autoimmunity, vol. 35, no. 8, pp. 555-564, 2002.

[32] J. M. Farrant, D. G. Doherty, P. T. Donaldson et al., "Amino acid substitutions at position 38 of the DR $\beta$ polypeptide confer susceptibility to and protection from primary sclerosing cholangitis," Hepatology, vol. 16, no. 2, pp. 390-395, 1992.

[33] A. Amar, C. Brautbar, E. Goldin et al., "Serological and molecular analysis of HLA in Israeli primary sclerosing cholangitis 
patients," European Journal of Immunogenetics, vol. 19, no. 5, pp. 295-302, 1992.

[34] O. Olerup, R. Olsson, R. Hultcrantz, and U. Broomé, "HLA-DR and HLA-DQ are not markers for rapid disease progression in primary sclerosing cholangitis," Gastroenterology, vol. 108, no. 3, pp. 870-878, 1995.

[35] M. H. K. Leidenius, S. A. Koskimies, I. H. Kellokumpu, and K. A. V. Hockerstedt, "HLA antigens in ulcerative colitis and primary sclerosing cholangitis," APMIS, vol. 103, no. 7-8, pp. 519-524, 1995.

[36] M. Wilschanski, P. Chait, J. A. Wade et al., "Primary sclerosing cholangitis in 32 children: clinical, laboratory, and radiographic features, with survival analysis," Hepatology, vol. 22, no. 5, pp. 1415-1422, 1995.

[37] K. M. Boberg, A. Spurkland, G. Rocca et al., "The HLADR3,DQ2 heterozygous genotype is associated with an accelerated progression of primary sclerosing cholangitis," Scandinavian Journal of Gastroenterology, vol. 36, no. 8, pp. 886-890, 2001.

[38] P. L. Bittencourt, S. A. Palacios, E. L. Cançado et al., "Susceptibility to primary sclerosing cholangitis in Brazil is associated with HLA-DRB1* 13 but not with tumour necrosis factor $\alpha-308$ promoter polymorphism," Gut, vol. 51, no. 4, pp. 609-610, 2002.

[39] T. M. Neri, G. M. Cavestro, P. Seghini et al., "Novel association of HLA-haplotypes with primary sclerosing cholangitis (PSC) in a southern European population," Digestive and Liver Disease, vol. 35, no. 8, pp. 571-576, 2003.

[40] J. R. Hov, A. Lleo, C. Selmi et al., "Genetic associations in Italian primary sclerosing cholangitis: heterogeneity across Europe defines a critical role for HLA-C," Journal of Hepatology, vol. 52, no. 5, pp. 712-717, 2010.

[41] P. Wang, H. Su, J. Underhill et al., "Autoantibody and human leukocyte antigen profiles in children with autoimmune liver disease and their first-degree relatives," Journal of Pediatric Gastroenterology and Nutrition, vol. 58, no. 4, pp. 457-462, 2014.

[42] S. Næss, B. A. Lie, E. Melum et al., "Refinement of the MHC risk map in a Scandinavian primary sclerosing cholangitis population," PLoS ONE, vol. 9, no. 12, Article ID el14486, 2014.

[43] K. Wiencke, T. H. Karlsen, K. M. Boberg et al., "Primary sclerosing cholangitis is associated with extended HLA-DR3 and HLA-DR6 haplotypes," Tissue Antigens, vol. 69, no. 2, pp. 161-169, 2007.

[44] T. H. Karlsen, K. M. Boberg, M. Olsson et al., "Particular genetic variants of ligands for natural killer cell receptors may contribute to the HLA associated risk of primary sclerosing cholangitis," Journal of Hepatology, vol. 46, no. 5, pp. 899-906, 2007.

[45] S. Norris, E. Kondeatis, R. Collins et al., "Mapping MHCencoded susceptibility and resistance in primary sclerosing cholangitis: the role of MICA polymorphism," Gastroenterology, vol. 120, no. 6, pp. 1475-1482, 2001.

[46] G. F. Mells, A. Kaser, and T. H. Karlsen, "Novel insights into autoimmune liver diseases provided by genome-wide association studies," Journal of Autoimmunity, vol. 46, pp. 41-54, 2013.

[47] C. A. O'Mahony and J. M. Vierling, "Etiopathogenesis of primarysclerosing cholangitis," Seminars of Liver Diseases, vol. 26, pp. 3-21, 2006.

[48] B. Xu, U. Broomé, B.-G. Ericzon, and S. Sumitran-Holgersson, "High frequency of autoantibodies in patients with primary sclerosing cholangitis that bind biliary epithelial cells and induce expression of CD44 and production of interleukin 6," Gut, vol. 51, no. 1, pp. 120-127, 2002.
[49] A. Karrar, U. Broomé, T. Södergren et al., "Biliary epithelial cell antibodies link adaptive and innate immune responses in primary sclerosing cholangitis," Gastroenterology, vol. 132, no. 4, pp. 1504-1514, 2007.

[50] S. P. O’Hara, P. L. Splinter, C. E. Trussoni, G. B. Gajdos, P. N. Lineswala, and N. F. LaRusso, "Cholangiocyte N-Ras protein mediates lipopolysaccharide-induced interleukin 6 secretion and proliferation," The Journal of Biological Chemistry, vol. 286, no. 35, pp. 30352-30360, 2011.

[51] E. Hashimoto, K. D. Lindor, H. A. Homburger et al., "Immunohistochemical characterization of hepatic lymphocytes in primary biliary cirrhosis in comparison with primary sclerosing cholangitis and autoimmune chronic active hepatitis," Mayo Clinic Proceedings, vol. 68, no. 11, pp. 1049-1055, 1993.

[52] T. L. Whiteside, S. Lasky, L. Si, and D. H. Van Thiel, "Immunologic analysis of mononuclear cells in liver tissues and blood of patients with primary sclerosing cholangitis," Hepatology, vol. 5, no. 3, pp. 468-474, 1985.

[53] J. A. Snook, R. W. Chapman, G. K. Sachdev et al., "Peripheral blood and portal tract lymphocyte populations in primary sclerosing cholangitis," Journal of Hepatology, vol. 9, no. 1, pp. 36-41, 1989.

[54] J.-P. Coppé, C. K. Patil, F. Rodier et al., "Senescence-associated secretory phenotypes reveal cell-nonautonomous functions of oncogenic RAS and the p53 tumor suppressor," PLoS Biology, vol. 6, no. 12, article e301, pp. 2853-2868, 2008.

[55] J. H. Tabibian, S. P. O'Hara, P. L. Splinter, C. E. Trussoni, and N. F. Larusso, "Cholangiocyte senescence by way of N-Ras activation is a characteristic of primary sclerosing cholangitis," Hepatology, vol. 59, no. 6, pp. 2263-2275, 2014.

[56] A. Panasiuk, D. Prokopowicz, J. Zak, B. Panasiuk, and J. Wysocka, "Lymphocyte subpopulations in peripheral blood in primary sclerosing cholangitis," Hepato-Gastroenterology, vol. 51, no. 59, pp. 1289-1291, 2004.

[57] X. Bo, U. Broomé, M. Remberger, and S. Sumitran-Holgersson, "Tumour necrosis factor $\alpha$ impairs function of liver derived $\mathrm{T}$ lymphocytes and natural killer cells in patients with primary sclerosing cholangitis," Gut, vol. 49, no. 1, pp. 131-141, 2001.

[58] M. Exley, J. Garcia, S. B. Wilson et al., "CD1d structure and regulation on human thymocytes, peripheral blood T cells, B cells and monocytes," Immunology, vol. 100, no. 1, pp. 37-47, 2000.

[59] E. Schrumpf, C. Tan, T. H. Karlsen et al., “The biliary epithelium presents antigens to and activates natural killer T cells," Нераtology, vol. 62, no. 4, pp. 1249-1259, 2015.

[60] B. Eksteen, A. J. Grant, A. Miles et al., "Hepatic endothelial CCL25 mediates the recruitment of CCR9 $9^{+}$gut-homing lymphocytes to the liver in primary sclerosing cholangitis," The Journal of Experimental Medicine, vol. 200, no. 11, pp. 1511-1517, 2004.

[61] A. J. Grant, P. F. Lalor, S. G. Hübscher, M. Briskin, and D. H. Adams, "MAdCAM-1 expressed in chronic inflammatory liver disease supports mucosal lymphocyte adhesion to hepatic endothelium (MAdCAM-1 in chronic inflammatory liver disease)," Hepatology, vol. 33, no. 5, pp. 1065-1072, 2001.

[62] A. Miles, E. Liaskou, B. Eksteen, P. F. Lalor, and D. H. Adams, "CCL25 and CCL28 promote $\alpha 4 \beta 7$-integrin- dependent adhesion of lymphocytes to MAdCAM-1 under shear flow," American Journal of Physiology-Gastrointestinal and Liver Physiology, vol. 294, no. 5, pp. G1257-G1267, 2008.

[63] K. Neumann, N. Kruse, B. Szilagyi et al., "Connecting liver and gut: murine liver sinusoidal endothelium induces gut tropism 
of $\mathrm{CD}^{+}{ }^{\mathrm{T}}$ cells via retinoic acid," Hepatology, vol. 55, no. 6, pp. 1976-1984, 2012.

[64] E. B. G. Martins, A. K. Graham, R. W. Chapman, and K. A. Fleming, "Elevation of gamma delta $\mathrm{T}$ lymphocytes in peripheral blood and livers of patients with primary sclerosing cholangitis and other autoimmune liver diseases," Hepatology, vol. 23, no. 5, pp. 988-993, 1996.

[65] M. Sebode, M. Peiseler, B. Franke et al., "Reduced FOXP3+ regulatory $\mathrm{T}$ cells in patients with primary sclerosing cholangitis are associated with IL2RA gene polymorphisms," Journal of Hepatology, vol. 60, no. 5, pp. 1010-1016, 2014.

[66] J. Katt, D. Schwinge, T. Schoknecht et al., "Increased T helper type 17 response to pathogen stimulation in patients with primary sclerosing cholangitis," Hepatology, vol. 58, no. 3, pp. 1084-1093, 2013.

[67] T. H. Karlsen, E. Schrumpf, and K. M. Boberg, "Genetic epidemiology of primary sclerosing cholangitis," World Journal of Gastroenterology, vol. 13, no. 41, pp. 5421-5431, 2007.

[68] R. Eri, J. R. Jonsson, N. Pandeya et al., "CCR5- $\Delta 32$ mutation is strongly associated with primary sclerosing cholangitis," Genes \& Immunity, vol. 5, no. 6, pp. 444-450, 2004.

[69] E. Melum, T. H. Karlsen, U. Broomé et al., “The 32-base pair deletion of the chemokine receptor 5 gene (CCR5- $\Delta 32)$ is not associated with primary sclerosing cholangitis in 363 Scandinavian patients," Tissue Antigens, vol. 68, no. 1, pp. 78-81, 2006.

[70] X. Yang, S. N. Cullen, J. H. Li, R. W. Chapman, and D. P. Jewell, "Susceptibility to primary sclerosing cholangitis is associated with polymorphisms of intercellular adhesion molecule-1," Journal of Hepatology, vol. 40, no. 3, pp. 375-379, 2004.

[71] K. Nakamura, K. Honda, T. Mizutani, H. Akiho, and N. Harada, "Novel strategies for the treatment of inflammatory bowel disease: selective inhibition of cytokines and adhesion molecules," World Journal of Gastroenterology, vol. 12, no. 29, pp. 4628-4635, 2006.

[72] E. Liaskou, L. E. Jeffery, P. J. Trivedi et al., "Loss of CD28 expression by liver-infiltrating $\mathrm{T}$ cells contributes to pathogenesis of primary sclerosing cholangitis," Gastroenterology, vol. 147, no. 1, pp. 221-232.e7, 2014. 


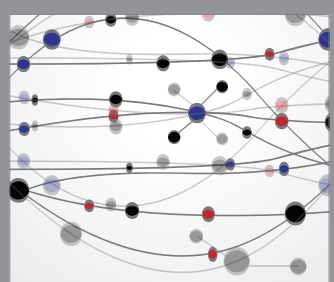

The Scientific World Journal
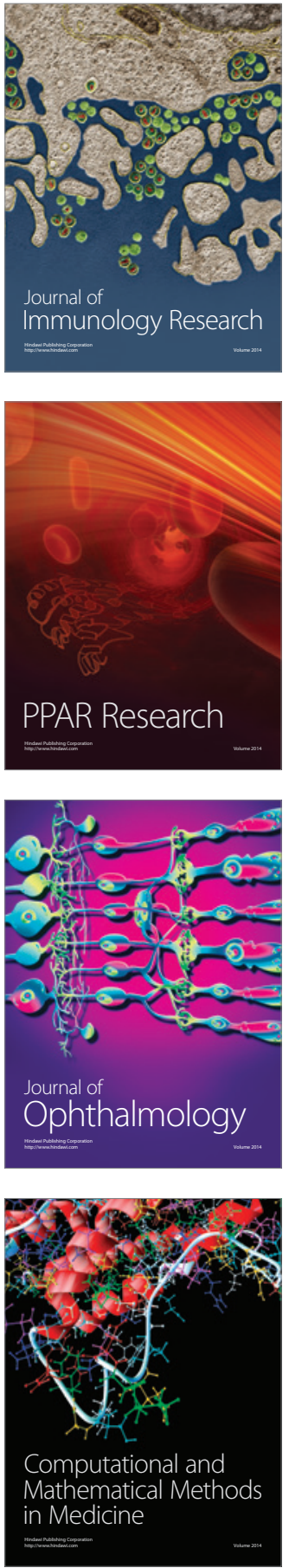

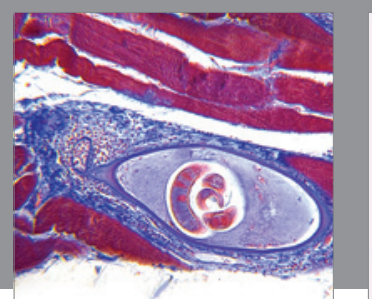

Gastroenterology Research and Practice

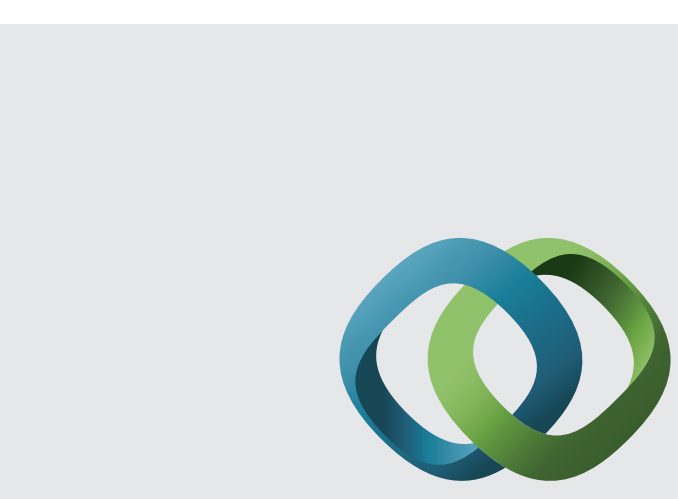

\section{Hindawi}

Submit your manuscripts at

http://www.hindawi.com
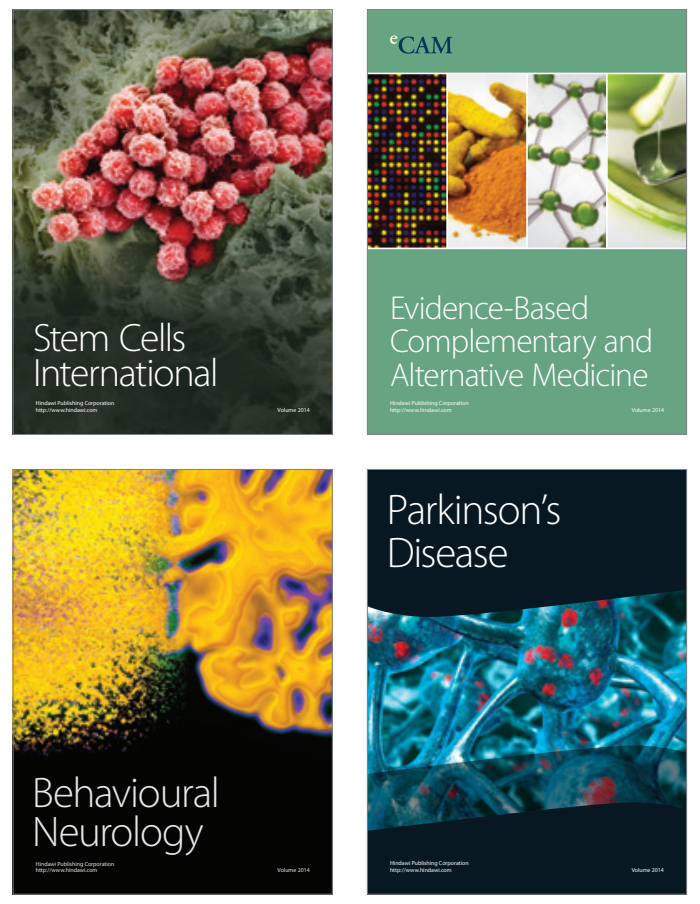
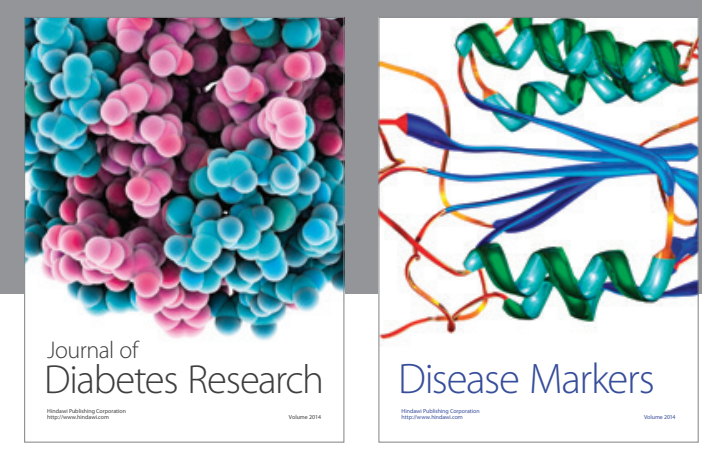

Disease Markers
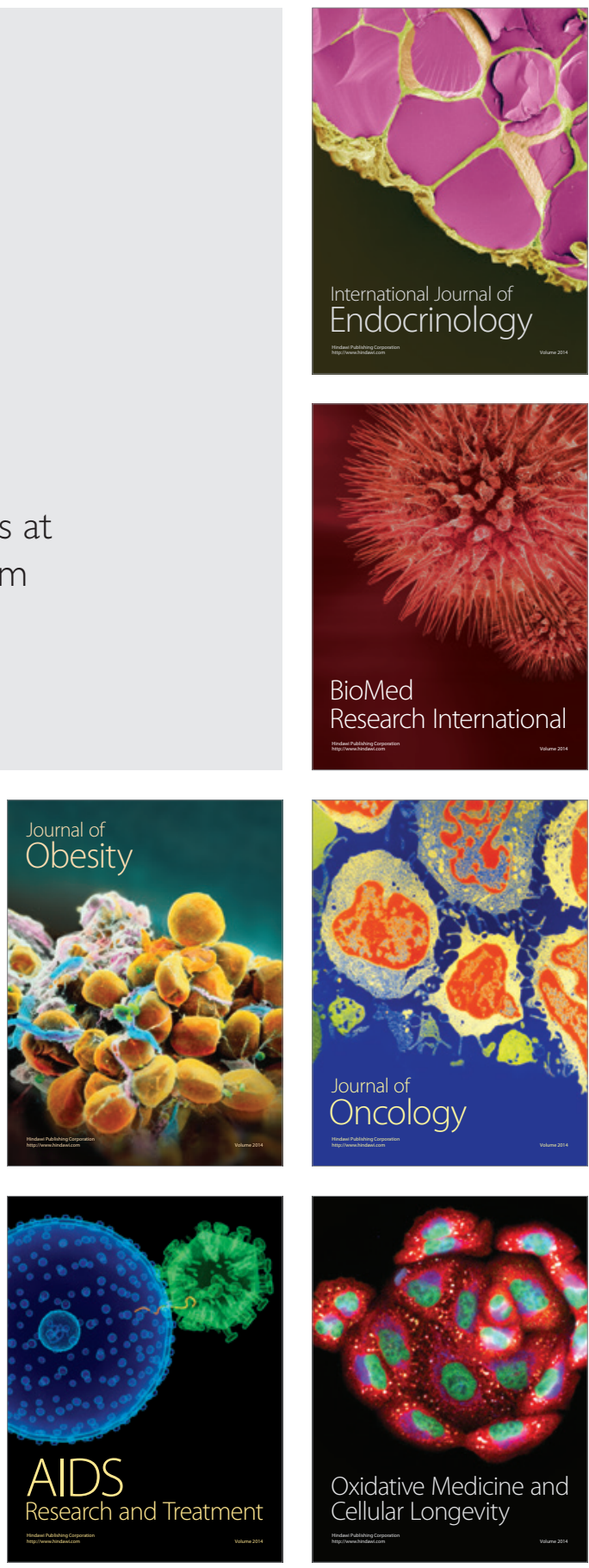